\title{
Famílias brasileiras na diáspora: fotografias
}

\author{
Denise Barros Weiss* \\ Maíra Candian**
}

\section{Resumo}

Este artigo tem como objetivo apresentar uma fotografia a partir de dados de 28 famílias de brasileiros(as) expatriados(as) que possuem filhos. Com base em Cummins (1983) e Mendes (2015), apresentamos os conceitos de Língua de Herança e de Português como Língua de Herança, respectivamente. Através de um formulário elaborado na plataforma Google Forms, obtivemos informações pessoais e linguísticas a respeito da constituição e interação dos membros de famílias diaspóricas formadas por pelo menos um adulto brasileiro. Investigamos as línguas utilizadas por essas famílias para compreender se o Português como Língua de Herança está se estabelecendo nesses lares. Analisamos também quais os esforços empreendidos pelo pai ou mãe brasileiro(a) para que aconteça a aprendizagem do português pelos filhos que estão crescendo e/ou nascendo no exterior. Concluímos que em famílias compostas por ambos os pais de mesma nacionalidade as condições são mais favoráveis à manutenção e ao uso da Língua Materna dos pais e de Herança dos filhos.

Palavras-chave: Língua de Herança. Diáspora brasileira. Políticas Linguísticas Familiares.

\footnotetext{
* Universidade Federal de Juiz de Fora (UFJF). Doutora e professora associada da UFJF. Pesquisadora de questões relacionadas à sala de aula de português para falantes não nativos em suas variadas possibilidades. ORCID ID: 0000-0003-1713-0947.

** Universidade Federal de Juiz de Fora (UFJF). Mestra e doutoranda em Linguística no Programa de Pós-Graduação em Linguística da UFJF. ORCID ID: 0000-0001-9184-3887.
} 


\title{
Brazilian families in the diaspora: photographs
}

\begin{abstract}
This article aims to present an overview based on data from twenty-eight families of expatriate Brazilians who have children. Based on Cummins (1983) and Mendes (2015), we introduce the concepts of Heritage Language and Portuguese as Heritage Language, respectively. Through a form created on the Google Forms platform, we obtained personal and linguistic information regarding the constitution and interaction of diasporic families formed by at least one Brazilian adult. We investigated the languages used by these families to understand whether Portuguese as a Heritage Language is establishing itself in these contexts. We also analyze the efforts made by the Brazilian father or mother to have their children, who are growing up/or being born abroad, learn Portuguese. We conclude that conditions are more favorable to the maintenance and use of the mother tongue of parents and the heritage language of the children in families composed of both parents of the same nationality.
\end{abstract}

Keywords: Heritage Language. Brazilian diaspora. Family Language Policies.

Recebido em: 17/03/2021 // Aceito em: 23/04/2021. 


\section{Introdução}

A diáspora brasileira é uma entre muitas movimentações de pessoas que ocorrem o tempo todo pelo mundo. Acelerada por crises econômicas, embalada por sonhos de uma vida melhor, a decisão de sair do país de origem nunca é fácil e isenta de conflitos. Um dos efeitos dessa mudança de vida é a decisão sobre a língua materna. Uma pessoa sozinha que vai para outro lugar pode não mais ter a chance de usá-la e assim ir perdendo o contato e o interesse por essa língua. Mas quando se tem ou se forma família com filhos, a casa pode se tornar lugar de uso dessa língua. Esse uso revela um pouco do sentimento da pessoa que migrou sobre seu passado, suas ligações com o lugar e as pessoas que ficaram. Revela, também, quando se observam as relações intrafamiliares, uma constelação de interesses de cada membro do grupo, com seus modos de ver as línguas - e não se pode ignorar o fortíssimo papel da comunidade de entorno.

Neste artigo, pretende-se apresentar imagens obtidas a partir de informações de 28 famílias que residem fora do Brasil, compostas por ao menos um adulto brasileiro. A partir da composição familiar, das línguas faladas dentro de cada família por cada membro, pretendemos obter uma ideia de como a língua portuguesa está sendo passada de uma geração para outra. Nosso foco é língua portuguesa como Língua de Herança (LH), mas, ao observarmos essas famílias, pensamos também em como as línguas dos emigrados são uma forma de resistência, de memória mantida mesmo em condições pouco favoráveis.

A metáfora da fotografia, neste artigo, procura colocar nossos dados na perspectiva de uma pesquisa que vê essas famílias sob um ângulo específico —o do respondente da 
pesquisa, que é um adulto brasileiro - e nos lembrar que esses dados representam um momento fugidio da vida dessas pessoas, possivelmente alterados de alguma maneira até pela pesquisa em si. Assim, vamos aqui descrever esse momento, mas não analisar profundamente suas implicações.

Começaremos por um olhar panorâmico sobre a formação desse conjunto de famílias, explicando como se chegou até eles e analisando elementos comuns ou frequentes. Depois passaremos a pequenos recortes, observando um pouco mais de perto determinadas configurações familiares e suas redes de linguagens.

\section{Fotografia panorâmica: cenário sociolinguístico}

Começamos pelo conceito de diáspora, procurando distingui-lo do de dispersão; eles são comumente associados por conta da palavra grega diasporá, traduzida por dispersão e por diáspora em português. Fred W. Riggs (2000) faz uma distinção entre os termos diáspora e dispersão, argumentando que a principal diferença é a assimilação do sujeito na sociedade anfitriã e a manutenção do contato com a sociedade pátria, explicando que diáspora está relacionada ao ato de manter contato com o país de origem, enquanto dispersão é somente o ato de sair da pátria e tornar-se parte da terra de acolhimento. Dessa forma, nas dispersões, os sujeitos podem se envolver com as características das sociedades majoritárias a ponto de perderem suas antigas identidades para assumirem novas identidades. No caso da pesquisa que apresentamos, analisamos famílias em que ao menos um membro informa ter intenção de manter viva a língua portuguesa, e nossas observações nos 
mostraram que seu companheiro, quando falante de outra língua, parece compartilhar dessa ideia, mantendo também viva a língua dele. Assim, acabamos por flagrar, nessas imagens, não uma nacionalidade em diáspora, mas possivelmente várias, em uma construção ainda mais complexa.

Ana Souza (2008), com base em Tajfel (1978), pontua que grupos minoritários, quando em contato com grupos majoritários, podem se comportar de três maneiras diferentes: como nativos, cosmopolitas e turistas. A primeira classificação, nativos, corresponde ao desejo de assimilação do grupo minoritário ao majoritário, com barreiras que os fazem fracassar. $\mathrm{O}$ segundo grupo, os cosmopolitas, é composto pelos sujeitos que conservam as principais características que os definem e que vêm de suas origens, mas que também perdem algumas delas. Já o terceiro grupo, os chamados turistas, são contra qualquer assimilação ao grupo majoritário, reagindo, inclusive, contra quem tentar se assimilar. Dessa maneira, o processo de se assimilar à sociedade majoritária é permeado por questões não só sociais, mas também culturais e linguísticas.

As Línguas de Herança se estabeleceram desde quando, em tempos remotos, as primeiras civilizações que emigraram decidiram que as crianças que cresceriam e/ou nasceriam em terras estrangeiras falariam aquela língua por ser mais do que a língua materna dos pais, um bem familiar que deveria ser transmitido às novas gerações. Enquanto área de estudos, Cummins (1983) foi o primeiro a cunhar o termo, definindo-o como a língua etnocultural de uma comunidade. ${ }^{1}$ Assim, o Português Língua de Herança (doravante PLH) é a língua portuguesa transmitida pela família em diáspora às gerações

1 Tradução do original: "Heritage language generally refers to the community ethnocultural language." (CUMMINS, 1983, p. 7). 
mais novas que nascem e/ou crescem em territórios de línguas diferentes do português. Segundo Mendes (2015, p. 79), “o PLH caracteriza-se pelos contextos em que o português e sua cultura são ensinados a filhos de luso-falantes imigrados, em diferentes partes do mundo, e representantes de diferentes línguas-culturas em português".

No contexto de línguas de herança, em que famílias preservam as raízes culturais e linguísticas do país de origem, observamos que a língua e cultura atuam como um forte símbolo de identidade social e étnica. "Manifestações de identidade nacional constituem-se, assim, em um marco de identidade coletiva que passa a ser recriada, re-imaginada, re-inventada e incorporada à construção de um novo cotidiano marcado pela ambiguidade da vida entre-lugares." (MOTA, 2008, p. 312). Essas manifestações formam um mosaico de situações marcadas por uma complexidade que não pode ser ignorada ou reduzida a números. A decisão de manter a língua e cultura pode ser influenciada por serem os membros dessa família ou da comunidade rotulados como "outros" pela sociedade majoritária em dois extremos: de uma forma negativa ou de uma forma positiva. Luk e Lin (2007) apontam que as línguas do mundo são frequentemente hierarquizadas: ser nativo de determinada língua pode permitir ao falante determinados privilégios e status de que um falante nativo de outra língua é impedido de desfrutar. “O falante pode, portanto, ostentar sua LH [Língua de Herança] a fim de se diferenciar na comunidade." (WEISS; FONSECA; DUTRA, 2018, p. 1.276).

Por um lado, em um extremo do continuum, há situações em que as LHs são forjadas pela resistência: "um coletivo que se sente culturalmente rejeitado ou social e politicamente 
marginalizado pela comunidade majoritária reage construindo com os materiais de sua história formas de autoidentificação"2 (MAKONI, 2018, p. 86, tradução nossa), através e na LH. A valorização da cultura e LH, nesse caso, pode ser uma resposta aos preconceitos sofridos e às experiências de rejeição vindas do grupo dominante e funciona como um símbolo de resistência. No outro extremo, há situações em que as LHs são protegidas pelo prestígio e status que a sociedade majoritária lhes confere; a comunidade de entorno aprecia o fato de ter no seu grupo pessoas que têm aquela cultura e que falam aquela língua.

As LHs são, portanto, um patrimônio que o falante carrega, como fardo ou símbolo de orgulho. Makoni (2018) afirma que desenvolver uma identidade de herança positiva é possuir a consciência não só do valor cultural e simbólico que as LHs têm, mas também do potencial de tornar a proficiência na LH em capital econômico no mercado global.

\section{A imigração brasileira nos últimos 20 anos}

Segundo o portal Brasileiros no Mundo, do Ministério das Relações Exteriores, na última estimativa populacional de comunidades brasileiras no exterior, realizada em novembro de 2016, havia aproximadamente 3,1 milhões de brasileiros expatriados. No entanto, o Itamaraty ressalta que esse número pode estar incompleto devido às migrações irregulares. Nos anos 80, também conhecidos como os "anos perdidos" devido à crise econômica que assolou o Brasil, os brasileiros intensificaram o fluxo imigratório para países desenvolvidos em busca de

\footnotetext{
2 Tradução do original: "a human collective that feels culturally rejected or socially or politically marginalized reacts by constructing with the materials of its history forms of self-identification". (MAKONI, 2018, p. 86).
} 
melhores condições de vida. Ainda de acordo com dados do portal, os brasileiros estão residindo atualmente nos cinco continentes, conforme mostra a Tabela 1, a seguir.

\section{Tabela 1 - Brasileiros pelo mundo}

\begin{tabular}{|c|c|c|c|}
\hline Continente & Total & $\begin{array}{c}\text { País com maior } \\
\text { concentração }\end{array}$ & $\begin{array}{c}\text { Número de } \\
\text { habitantes }\end{array}$ \\
\hline África & 25.387 & Angola & 15.000 \\
América & 2.025 .086 & Estados Unidos & 1.410 .000 \\
Ásia e Oriente & 239.489 & Japão & 170.229 \\
Médio & & & 120.000 \\
Europa & 750.983 & Reino Unido & 37.310 \\
Oceania & 47.310 & Austrália & \\
\hline
\end{tabular}

Fonte: Dutra (2021, p. 30).

Os países que possuem maior concentração de brasileiros em cada continente são Angola, Estados Unidos, Japão, Reino Unido e Austrália. Com respeito às línguas majoritárias desses países, percebemos que, com exceção de Angola, em que a língua oficial é o português, as línguas oficiais desses países inglês e japonês - são consideradas de prestígio em virtude da influência econômica e política que exercem mundialmente nesse momento. O português como língua minoritária nessas sociedades, portanto, possui um status de menor valor diante das línguas majoritárias que são consideradas de prestígio.

Somando-se os cinco grupos, são mais de três milhões de brasileiros oficialmente expatriados. Cada um deles que, fora do país, forma uma família e tem filhos vai criar uma nova possibilidade de difusão da língua portuguesa para essa segunda geração. Há um mosaico de possibilidades e configurações familiares que pode existir nas casas de brasileiros expatriados. Pensando a partir somente da nacionalidade, considerando nosso 
caso em tela, o PLH falado em famílias da diáspora formadas por ao menos um brasileiro, temos três combinações básicas de pares de adultos constituindo família: brasileiros com parceiros brasileiros, brasileiros com parceiros nativos do país anfitrião e brasileiros com parceiros estrangeiros na mesma condição de expatriados. Nossa pesquisa visa a verificar como essas combinações afetam a política linguística familiar.

A manutenção de uma língua minoritária, mesmo que em ambientes restritos, perpassa questões culturais, sociais e identitárias. Nossa pesquisa teve como um de seus eixos a análise das razões pelas quais se pretende preservar a língua materna para a próxima geração da família. Ana Souza (2008), em pesquisa com mães brasileiras residentes em Londres, investigou alguns fatores que poderiam influenciar as suas escolhas linguísticas, a saber: sucesso socioeconômico, contatos com a comunidade do país anfitrião e do país de origem, atitudes linguísticas e contextos de usos de línguas. As 13 mães pesquisadas pela autora relataram que a identidade é um aspecto que desempenha um papel importante na hora de determinar quais línguas serão usadas em casa. O posicionamento dessas mães diante da comunidade majoritária e suas percepções sobre si atuaram como determinantes na hora de eleger (ou não) o português como uma língua da casa. Outro fator atrelado à identidade e que também influencia nas escolhas linguísticas familiares é a conexão afetiva com a língua, cultura e país de origem. Há migrantes que tendem a deixar de lado suas raízes pelo que essa bagagem representa para eles na vida que se (re) inicia em outro país.

Além disso, em virtude do capital econômico que as línguas podem simbolizar, o status que a língua minoritária possui 
na comunidade de entorno também é um aspecto decisivo da política linguística familiar. Para ilustrar, um norte-americano que se muda para o Brasil e constitui uma família certamente terá o inglês como uma língua a ser falada em casa. Os filhos, portanto, desenvolverão o inglês como LH e possivelmente terão orgulho desse traço identitário herdado do pai. Da mesma maneira, um brasileiro que migra para os Estados Unidos e lá forma sua família terá sua língua inclusa no ambiente familiar?

\section{0 instrumento de coleta de dados}

\subsection{Origem dos dados}

A coleta de dados para esta pesquisa, que constituiu a dissertação de mestrado de uma das autoras, foi feita através de um procedimento de caráter digital. Elaboramos um formulário na plataforma Google Forms e o compartilhamos através da rede social Facebook em grupos e páginas sobre o ensino/aprendizagem de língua portuguesa no exterior. ${ }^{3}$ Nossa principal limitação para a distribuição do questionário foi a distância geográfica do nosso público-alvo, que era composto de brasileiro ou brasileira residente no exterior e que possui filhos. Por isso adotamos essa técnica — não havia possibilidade de um encontro com eles.

O questionário era composto de 19 perguntas objetivas e duas perguntas descritivas, nas quais buscamos investigar em que condições o PLH está se desenvolvendo nessas famílias. As

\footnotetext{
3 Originalmente o formulário foi veiculado no grupo "Ensinar Português como Segunda Língua" (C.f.: https://www.facebook. com/groups/122030394508584 ) e depois compartilhado na rede pelos próprios participantes desse grupo, em uma cadeia de divulgação que não é controlável.
} 
questões versavam sobre as escolhas linguísticas da família e sobre sua inserção nas comunidades majoritária e minoritária no caso da existência de uma comunidade brasileira no exterior. Além disso, havia questões cujo objetivo era obter informações pessoais sobre a família, como sua composição e a nacionalidade do(a) parceiro(a) da(o) participante. Esse questionário está disponível, como anexo, no final deste artigo.

\section{Fotografias de algumas famílias vivendo na diáspora}

Nesta seção, mostramos uma seleção de dados sobre as 28 famílias que responderam ao nosso questionário, cruzando informações sobre o país de origem de cada parceiro dos informantes, o país de acolhimento e as línguas faladas pelos membros da família - dos adultos entre si, de cada adulto com os filhos, do filhos com cada adulto e por fim dos filhos entre si. Salientamos que a nacionalidade de todos os respondentes da pesquisa é brasileira; esse era um dos pré-requisitos para se responder ao questionário. Essa informação não consta da tabela por ser igual para todas as famílias e por questões gráficas. Não investigamos a situação de cidadania dos filhos e consideramos somente a declaração do adulto sobre a composição das línguas empregadas pelos filhos, não a nacionalidade das crianças.

Apresentamos os dados em dois blocos, para facilitar a visualização, mas também para podermos observar a situação especificamente quando se trata de famílias com brasileiros vivendo nos Estados Unidos, pois esse era o maior grupo entre os respondentes. Nesse grupo, obtivemos os dados que compõem a tabela a seguir. 


\section{Tabela 2 - Famílias residentes nos Estados Unidos}

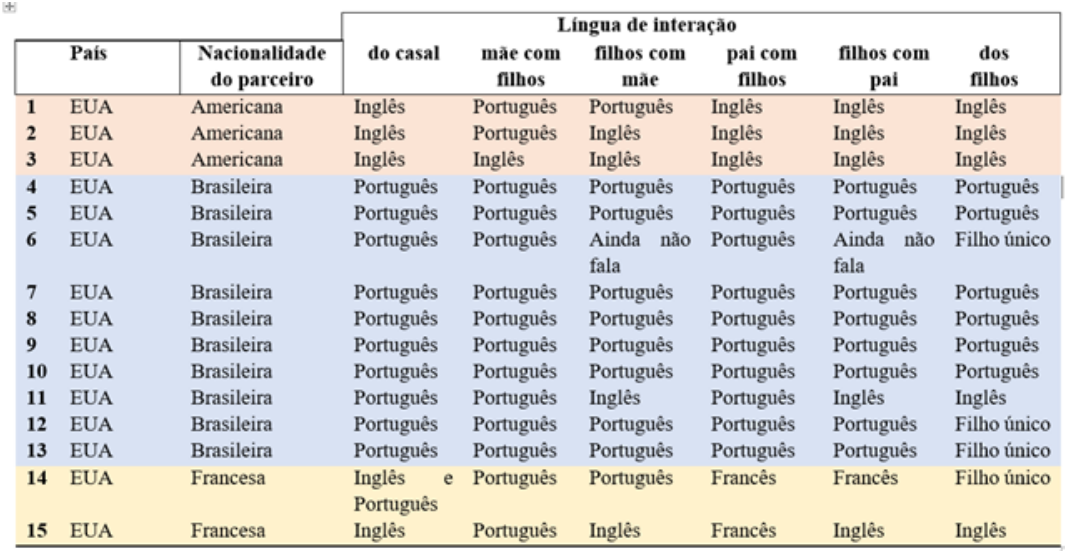

Fonte: Elaborada pelas autoras, adaptada de Dutra (2021).

Inicialmente, distinguimos as famílias formadas por ambos os adultos brasileiros daquelas formadas por casal de origens diferentes. Em rosa, estão as famílias formadas por brasileiro - estadunidense; em azul, famílias formadas por ambos adultos brasileiros; em laranja, as famílias formadas por brasileiro francês. No grupo brasileiro - brasileiro, o português é empregado pelos adultos entre si, mas se percebe um movimento, por parte dos filhos, em uma família, que indica o uso da língua majoritária para conversar mesmo em casa (11). No grupo formado por brasileiro e americano, a língua majoritária já ganha muito mais espaço, por ser de um dos cônjuges. No grupo formado por brasileiro e francês, três línguas entram em concorrência: o filho único responde ao pai e à mãe nas suas línguas maternas (14) ou os filhos usam a língua majoritária, enquanto os adultos usam suas línguas maternas (15).

Nesse grupo, percebe-se que a força da língua de origem dos adultos só se soma no caso de os dois usarem a mesma - 
caso contrário, a língua majoritária vai ser empregada pelos filhos, exceto o filho que usa suas LHs na interação com cada adulto (14). No caso dessa exceção, nota-se como se dá a escolha linguística desse sujeito bilíngue: ele responde ao pai e à mãe na mesma língua em que os escuta. Flagramos a preservação de duas LHs nessa família.

Apresentamos, a seguir, os dados correspondentes às famílias que residem em outros 10 países, destacados por cores distintas na Tabela 3. Alemanha, Irlanda, Inglaterra, Espanha, Suécia, Bélgica e Holanda, na Europa; Japão, na Ásia; México, na América do Norte; e Peru, na América do Sul.

\section{Tabela 3 - Famílias residentes em outros países}

\begin{tabular}{|c|c|c|c|c|c|c|c|c|}
\hline & \multirow{2}{*}{\multicolumn{6}{|c|}{ Lingua de interação }} \\
\hline & & & & & & & & \\
\hline & Pais & $\begin{array}{l}\text { Nacionalidade } \\
\text { do parceiro }\end{array}$ & do casal & $\begin{array}{l}\text { mãe com } \\
\text { filhos }\end{array}$ & $\begin{array}{l}\text { filhos com } \\
\text { mãe }\end{array}$ & $\begin{array}{c}\text { pai com } \\
\text { filhos }\end{array}$ & $\begin{array}{c}\text { filhos com } \\
\text { pai }\end{array}$ & $\begin{array}{l}\text { dos } \\
\text { filhos }\end{array}$ \\
\hline 16 & Alemanha & Brasileira & Português & Português & Português & Português & Português & Filho único \\
\hline 17 & Alemanha & Brasileira & Português & Português & Português & Português & Português & Fillho único \\
\hline 18 & Irlanda & Brasileira & Português & Português & Português & Português & Português & Filho único \\
\hline 19 & Inglaterra & Brasileira & Português & Português & Português & Português & Português & Filho único \\
\hline 20 & México & Brasileira & Português & Português & Português & Português & Português & Português \\
\hline 21 & Japão & Brasileira & Português & Português & Japonês & Português & Japonês & Japonês \\
\hline 22 & Japão & Japonesa & Japonês & Japonês & Japonês & Japonês & Japonês & Japonês \\
\hline 23 & Espanha & Espanhola & Espanhol & Português & $\begin{array}{l}\text { Ainda não } \\
\text { fala }\end{array}$ & Espanhol & $\begin{array}{l}\text { Ainda não } \\
\text { fala }\end{array}$ & Filho único \\
\hline 24 & Espanha & Espanhola & Espanhol & Português & Espanhol & Espanhol & Espanhol & Filho único \\
\hline 25 & Suécia & Sueca & Sueco & Português & Português & Sueco & Sueco & Filho único \\
\hline 26 & Bélgica & Belga & Português & Português & Português & Holandês & Português & Português \\
\hline 27 & Peru & Inglesa & $\begin{array}{l}\text { Inglès e } \\
\text { Português }\end{array}$ & Português & $\begin{array}{l}\text { Ainda não } \\
\text { fala }\end{array}$ & Inglês & $\begin{array}{l}\text { Ainda não } \\
\text { fala }\end{array}$ & Filho único \\
\hline 28 & Holanda & $\begin{array}{l}\text { Iraniana- } \\
\text { canadense }\end{array}$ & Inglês & Português & $\begin{array}{l}\text { Ainda não } \\
\text { fala }\end{array}$ & Persa & $\begin{array}{l}\text { Ainda não } \\
\text { fala }\end{array}$ & $\begin{array}{l}\text { Ainda não } \\
\text { fala }\end{array}$ \\
\hline
\end{tabular}

Fonte: Elaborada pelas autoras, adaptada de Dutra (2021).

Observando as línguas faladas pelos adultos entre si, permanece o padrão de uso do português quando ambos são brasileiros. Quando isso não acontece, prevalece a língua majoritária, quando ela coincide com a do parceiro estrangeiro $(22,23,24$ e 25$)$, exceto no caso da família residente na Bélgica, 
em que se fala português (26). A família residente no Peru oscila entre as línguas maternas dos parceiros (27), e o único caso de uma língua diferente é o da família residente na Holanda, em que se usa inglês como língua entre os parceiros (28).

A fala dos filhos com os pais segue o padrão também visto no grupo norte-americano. Adultos brasileiros falando português têm filhos falantes de português em casa. Quando as nacionalidades e as línguas maternas variam, há uma oscilação nas preferências - ou falam a língua majoritária (que está, nesse grupo, coincidindo com a do parceiro não brasileiro) ou se alterna entre as línguas maternas dos dois. Em um caso, o parceiro belga fala português com a brasileira e holandês com o filho, que responde em português aos dois (26).

Observando as duas tabelas, há dois casos de a língua portuguesa ser utilizada mesmo por parceiros estrangeiros (14, 28). Nessas casas, ambos os adultos são expatriados e utilizam duas línguas na interação entre si, sendo o português uma delas, e a língua majoritária ou a língua materna do parceiro, a outra.

$\mathrm{Na}$ Tabela 4, organizamos os dados para destacar a língua falada pelos filhos com seus pais e entre si (quando há mais de um). Em laranja, deixamos as famílias cujos filhos ainda não falam. Em azul, as famílias cujos filhos empregam o português para falar com seus pais. Em verde, as famílias cujos filhos usam outra língua para falar com seus pais. 


\section{Tabela 4 - Informações gerais sobre as famílias}

\begin{tabular}{|c|c|c|c|c|c|c|c|c|}
\hline & & \multicolumn{6}{|c|}{ Lingua de interação } & \multirow[b]{2}{*}{$\begin{array}{l}\text { Idade } \\
\text { filhos }\end{array}$} \\
\hline & $\begin{array}{c}\text { Nac. do } \\
\text { parceiro }\end{array}$ & do casal & $\begin{array}{c}\text { mãe com } \\
\text { filhos }\end{array}$ & $\begin{array}{c}\text { filhos com } \\
\text { mãe }\end{array}$ & $\begin{array}{c}\text { pai com } \\
\text { filhos }\end{array}$ & $\begin{array}{c}\text { filhos com } \\
\text { pai }\end{array}$ & $\begin{array}{c}\text { dos } \\
\text { filhos }\end{array}$ & \\
\hline 1 & EUA & Inglês & Português & Português & Inglês & Inglês & Inglês & $1 \mathrm{a} 6 \mathrm{~m} / 5 \mathrm{a}$ \\
\hline 2 & EUA & Inglês & Português & Inglês & Inglês & Inglês & Inglês & $6 a / 8 a$ \\
\hline 3 & EUA & Inglês & Inglês & Inglês & Inglês & Inglês & Inglês & $14 \mathrm{a} / 15 \mathrm{a}$ \\
\hline 4 & Brasileira & Português & Português & Português & Português & Português & Português & $12 a / 15 a$ \\
\hline 5 & Brasileira & Português & Português & Português & Português & Português & Português & $3 a / 5 a$ \\
\hline 6 & Brasileira & Português & Português & $\begin{array}{l}\text { Ainda não } \\
\text { fala }\end{array}$ & Português & $\begin{array}{l}\text { Ainda não } \\
\text { fala }\end{array}$ & Filho único & $10 \mathrm{~m}$ \\
\hline 7 & Brasileira & Português & Português & Português & Português & Português & Português & $\begin{array}{l}1 \mathrm{a} 1 \mathrm{~m} \\
10 \mathrm{a}\end{array}$ \\
\hline 8 & Brasileira & Português & Português & Português & Português & Português & Português & $8 a / 10 a$ \\
\hline 9 & Brasileira & Português & Português & Português & Português & Português & Português & $3 a / 6 a$ \\
\hline 10 & Brasileira & Português & Português & Português & Português & Português & Português & $5 \mathrm{a} / 10 \mathrm{a}$ \\
\hline 11 & Brasileira & Português & Português & Inglês & Português & Inglês & Inglês & $\begin{array}{l}12 a / 16 a / \\
22 a\end{array}$ \\
\hline 12 & Brasileira & Português & Português & Português & Português & Português & Filho único & $6 a$ \\
\hline 13 & Brasileira & Português & Português & Português & Português & Português & Filho único & $14 a$ \\
\hline 14 & Francesa & $\begin{array}{l}\text { Inglês e } \\
\text { Português }\end{array}$ & Português & Português & Francês & Francês & Filho único & $6 a$ \\
\hline 15 & Francesa & Inglês & Português & Inglês & Francês & Inglês & Inglês & $18 \mathrm{a} / 22 \mathrm{a}$ \\
\hline 16 & Brasileira & Português & Português & Português & Português & Português & Filho único & $3 a$ \\
\hline 17 & Brasileira & Português & Português & Português & Português & Português & Filho único & $2 \mathrm{a} 6 \mathrm{~m}$ \\
\hline 18 & Brasileira & Português & Português & Português & Português & Português & Filho único & $3 a$ \\
\hline 19 & Brasileira & Português & Português & Português & Português & Português & Filho único & $8 \mathrm{~m}$ \\
\hline 20 & Brasileira & Português & Português & Português & Português & Português & Português & $4 a / 7 a$ \\
\hline 21 & Brasileira & Português & Português & Japonês & Português & Japonês & Japonês & $10 \mathrm{a} / 13 \mathrm{a}$ \\
\hline 22 & Japonesa & Japonês & Japonês & Japonês & Japonês & Japonês & Japonês & $\begin{array}{l}6 a / 9 a / \\
11 a\end{array}$ \\
\hline 23 & Espanhola & Espanhol & Português & $\begin{array}{l}\text { Ainda não } \\
\text { fala }\end{array}$ & Espanhol & $\begin{array}{l}\text { Ainda não } \\
\text { fala }\end{array}$ & Filho único & $7 \mathrm{~m}$ \\
\hline 24 & Espanhola & Espanhol & Português & Espanhol & Espanhol & Espanhol & Filho único & $8 a$ \\
\hline 25 & Sueca & Sueco & Português & Português & Sueco & Sueco & Filho único & $3 \mathrm{a} 6 \mathrm{~m}$ \\
\hline 26 & Belga & Português & Português & Português & Holandês & Português & Português & $2 \mathrm{a} / 4 \mathrm{a}$ \\
\hline 27 & Inglesa & $\begin{array}{l}\text { Inglês e } \\
\text { Português }\end{array}$ & Português & $\begin{array}{l}\text { Ainda não } \\
\text { fala }\end{array}$ & Inglês & $\begin{array}{l}\text { Ainda não } \\
\text { fala }\end{array}$ & Filho único & $1 \mathrm{a} 2 \mathrm{~m}$ \\
\hline 28 & $\begin{array}{l}\text { Iraniana- } \\
\text { canadense }\end{array}$ & Inglês & Português & $\begin{array}{l}\text { Ainda não } \\
\text { fala }\end{array}$ & Persa & $\begin{array}{l}\text { Ainda não } \\
\text { fala }\end{array}$ & $\begin{array}{l}\text { Ainda não } \\
\text { fala }\end{array}$ & $0 \mathrm{a} / 1 \mathrm{a}$ \\
\hline
\end{tabular}

Fonte: Elaborada pelas autoras, adaptada de Dutra (2021).

De modo geral, observamos que os filhos tendem a falar com seus pais em português quando pais e mães são brasileiros ou, no caso da família 26, falam português entre si. Em caso de famílias com adultos de mais de uma nacionalidade, ou os filhos falam a língua de entorno, ou uma língua com cada adulto.

Entretanto, queríamos observar casos em que, mesmo com dois brasileiros adultos falando português, os filhos usavam a língua majoritária ao responderem (11 e 21). Nesses dois casos, 
o que há em comum é a idade dos filhos, compatível com escolarização e chegada da adolescência. Esse comportamento costuma acontecer porque as influências externas vão ficando muito mais fortes a partir do momento em que interações sociais fora do âmbito familiar ganham relevância na vida da criança.

\section{Como se incentiva o uso do português?}

As tabelas anteriores mostraram o que estava acontecendo nas famílias em termos linguísticos. Agora, observamos um pouco do modo pelo qual o membro adulto brasileiro dessas famílias procura manter o português vivo dentro de seu núcleo familiar. Para isso, usamos os dados advindos das duas únicas perguntas abertas do questionário enviado: 1 . Por que você considera importante que seus filhos saibam falar Português? 2. O que você faz para incentivar seus filhos a falarem português?

As 56 respostas recebidas para essas duas perguntas finais apresentam elementos semelhantes. A justificativa que os respondentes dão para a importância do aprendizado de português pelos filhos e os incentivos dados para esse aprendizado se aproximavam em vários aspectos. Por isso, elaboramos gráficos em que essas semelhanças bem como a frequência com que aparecem podem ser visualizadas.

Na primeira pergunta - Por que você considera importante que seus filhos saibam falar português? - , as motivações apresentadas foram de ordem comunicacional, cultural e identitária.

A comunicação com a família no Brasil estava na maioria das respostas e se apresenta como um dos maiores motivos pelos quais o respondente da pesquisa anseia que os filhos 
saibam falar português. Em seguida, o conhecimento das raízes identitárias e culturais da família e a importância do bilinguismo foram manifestados em oito das respostas. Quatro respondentes usaram as expressões língua materna e dois, LH, para descrever a motivação para o aprendizado da língua pelos filhos, descrevendo como os filhos se posicionam diante do português. Por fim, o aspecto afetivo também está entre as motivações relatadas pelos participantes. A língua materna na diáspora se torna a língua da lembrança, lengua del cuore (WEISS; CANDIAN, 2019). Para exemplificar, algumas das respostas foram transcritas a seguir:

(1.1) Português é minha primeira língua, é a conexão delas com a nossa família que mora no Brasil. É também a conexão com a minha identidade que quero que minhas filhas conheçam e entendam.

(9.1) Para que tenham a vantagem profissional de manter uma segunda língua, para manter um pouco da raiz brasileira e também ajudar no relacionamento com a família que está no Brasil.

(24.1) Pra manter suas raízes, é parte da sua identidade. Além do mais, facilita a comunicação com a família brasileira.

A frequência com que os dados descritos aparecem nas respostas pode ser visualizada no gráfico a seguir. 


\section{Figura 1 - Motivações relatadas para o aprendizado de português pelos filhos}

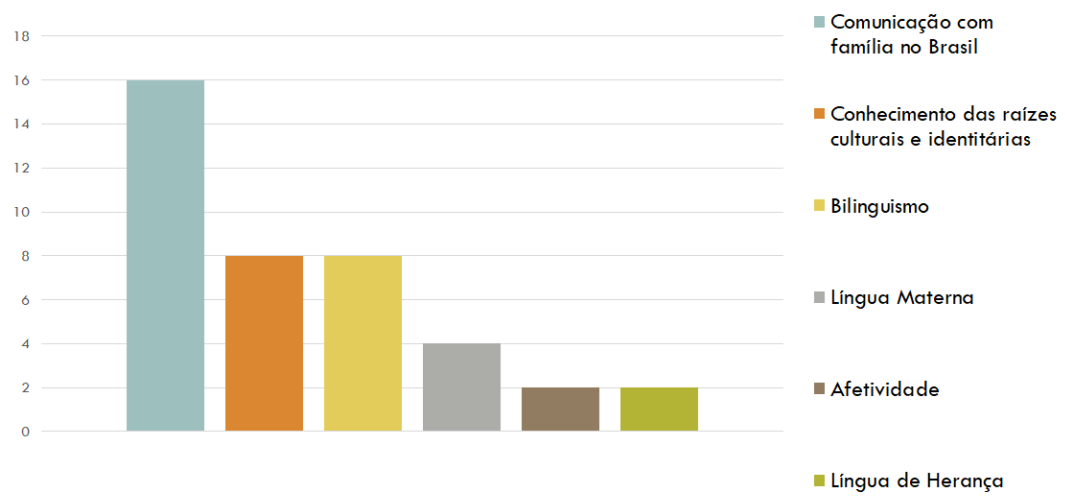

Fonte: Elaborado pelas autoras.

Na segunda pergunta - O que você faz para incentivar seus filhos a falarem português? - os respondentes se guiaram em parte pelas sugestões dadas no questionário, mas tinham a possibilidade de informar algo diferente. Nas respostas, observamos que a maior parte do que foi caracterizado como incentivo foi o fato de se usar o português na conversa interfamiliar. Além das conversas cotidianas em casa, houve, pela ordem de frequência nas respostas, interações com elementos culturais (livros, filmes, gibis, músicas, entre outros), interações com a família no Brasil (possibilitadas pelo uso das tecnologias da internet), estudo formal da língua (há filhos matriculados em escola com currículo bilíngue e filhos com aulas de português aos sábados), bem como interações com amigos brasileiros e lusófonos também em diáspora. Eis algumas das respostas para ilustrar:

(2.2) Falo em português, eles frequentam aula de português aos sábados, viagens anuais ao Brasil. 
(10.2) Converso com elas, sobre tudo e um pouco mais. Lemos todos os dias, nem que seja por $5 \mathrm{~min}$. Temos livros e revistas por toda a casa. Elas já amanhecem com revistas da Mônica na mão. Mas o que considero mais importante é o diálogo. Elas me contam tudo tintim por tintim, sem eu obrigar, naturalmente elas gostam de conversar. Se estamos num grupo que só fala inglês, comigo elas falam em português, automaticamente.

(28.2) Falo exclusivamente em português, leio livros em português, organizo play dates com crianças de outras famílias lusófonas.

Analisando o gráfico a seguir, percebemos a enorme prevalência do contato com a língua portuguesa somente no interior da casa. Esses dados indicam, possivelmente, famílias com pouca interação social em comunidades de fala portuguesa, seja porque elas estão isoladas em um contexto de língua majoritária, seja porque os filhos não interagem nessa comunidade. A escola, de alguma forma, supre essa demanda por contato com a língua.

\section{Figura 2 - Incentivos dados para os filhos aprenderem português}

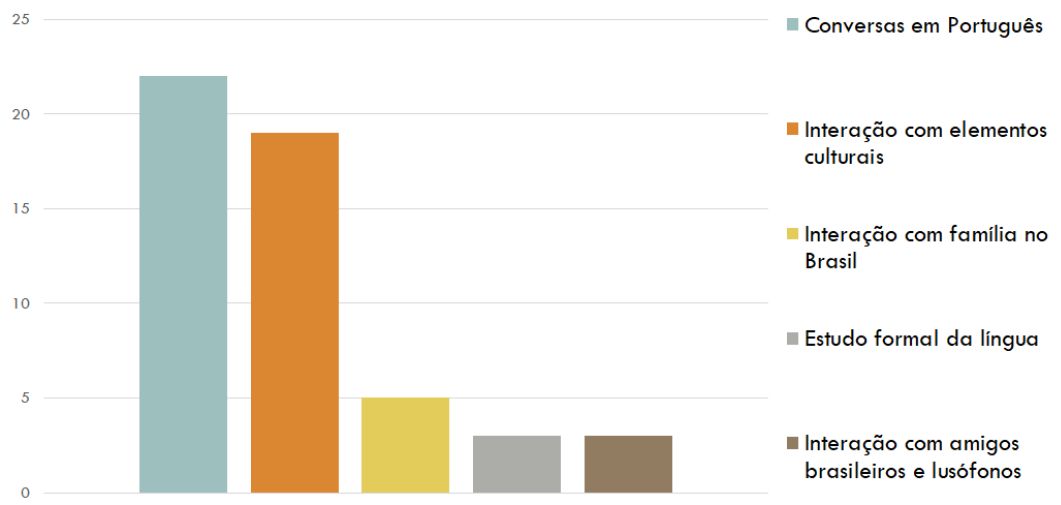

Fonte: Elaborado pelas autoras. 
Os participantes relataram que o principal motivo pelo qual desejam que os filhos saibam falar português é a comunicação com a família no Brasil e a principal maneira como incentivam o aprendizado da língua é através de interações e conversas em casa; além disso, a interação com a família no Brasil também está nos relatos. Ser bilíngue e conhecer as raízes culturais e identitárias da família também foram motivos revelados nas respostas.

Prevalece nas respostas a ideia de que a língua portuguesa é um laço mais afetivo do que utilitário na comunicação cotidiana. As respostas sugerem que, no modo de ver dos adultos, a língua tem uma função ligada às conexões com as raízes familiares. Para os filhos, essa pode ser uma motivação menos forte. Seu contato com essa família que mora longe é menos relevante que a vida cotidiana no país de adoção. Conversar com primos e avós pode ser difícil e os laços emocionais com eles vão se diluindo com o tempo, por mais que haja incentivo. Esse efeito da distância física e social pode ter consequências nas escolhas linguísticas quando eles vão ficando mais crescidos.

Para os pais que pretendem manter essa língua, há uma projeção diferente, uma expectativa da LH para o futuro: (25.1) "Incentivo meus filhos a falarem português para inseri-los na nossa cultura, para um futuro com mais possibilidades de emprego e viagens, para que possam comunicar com a família do Brasil."

\section{Conclusões}

Famílias têm dinâmicas próprias que variam conforme múltiplos fatores. As famílias diaspóricas cujos dados temos aqui 
demonstram isso. O movimento que gera a LH, nesse grupo, está ligado à manifestação dos participantes de que seus filhos vão carregar consigo o legado da língua portuguesa.

O grupo que analisamos está todo em lugares em que a língua da comunidade circundante é muito forte. Inglês, japonês, espanhol têm projeção mundial. As famílias compostas só por brasileiros têm na própria casa um nicho que resiste à interferência externa, em termos linguísticos. Por outro lado, nas famílias em que o português é falado somente por um dos membros adultos como língua materna, há uma concorrência e aí, se a língua majoritária é a do outro membro do par, ela se torna a preferida dos filhos. Não tivemos, nesse grupo, muitas situações em que há três línguas em concorrência — mas quando isso acontece, os filhos passam para a língua hegemônica.

Fizemos uma análise que cruzava os dados das idades dos filhos com as línguas que falavam com os pais. O resultado, embora muito incipiente, apontou para uma possível correlação entre a entrada na escola, e, portanto, o contato mais estreito e contínuo com a língua majoritária, e o uso dessa língua com os pais. Esse movimento é bastante prevalente nas situações de bilinguismo. Entretanto, vimos ao menos uma família em que a idade não pareceu interferir no uso da língua portuguesa.

Em um mundo no qual comportamentos, vestimentas, alimentação e línguas divergentes do padrão de uma comunidade podem ser vistos como destoantes e estranhos, a manutenção é uma forma de resistência ao apagamento. Por isso, foi com alegria que essas pesquisadoras viram que, ao menos sob o ponto de vista dos brasileiros que fizeram a gentileza de preencher nosso formulário, a lengua del cuore pulsa forte nas casas em que se procura mantê-la viva. Esperamos que este texto 
possa inspirar aqueles que continuam insistindo no uso de sua língua, pela compreensão de como a política linguística familiar funciona e pelos exemplos de manutenção dessa língua, mesmo em situações nas quais os motivos práticos levariam ao uso da língua majoritária. Permitir aos filhos a experiência com essas línguas é lhes dar uma oportunidade de enriquecimento cultural e fortalecer seu sentimento de pertença a uma comunidade que, embora seja distante fisicamente, compõe o conjunto de suas características pessoais.

\section{Referências}

BRASILEIROS no mundo. Itamaraty. Disponível em: $<$ http:// www.portalconsular.itamaraty.gov.br/no-exterior/brasileirosno-mundo>. Acesso em: 22 dez. 2020.

CUMMINS, J. Heritage language education: a literature review. Toronto: Ontario Inst. for Studies in Education, Ontario Dept. of Education, 1983.

DUTRA, M. C. P. Português como Língua de Herança: famílias na diáspora brasileira e sua relação com a Língua Portuguesa. 2021. 129 f. Dissertação (Mestrado em Linguística)

- Faculdade de Letras, Universidade Federal de Juiz de Fora, Juiz de Fora, 2021.

LUK, J. C. M.; LIN, A. M. Y. The Native-Speaking English Teachers in the Global ELT Industry. In: Classroom Interactions as Cross-Cultural Encounters: native speakers in ESL lessons. New Jersey. Routledge, 2007. p. 21-32.

MAKONI, B. Beyond country of birth: heritage languages learning and the discursive construction of identities of resistance. Heritage Language Journal, [s. l.], v. 15, n. 1, p. 71-94, 2018. 
MENDES, E. Ensino e formação de professores de Português como Língua de Herança (PLH): revisitando ideias, projetando ações. In: CHULATA, K. A. (org.) Português como Língua de Herança: discursos e percursos. Itália: Pensa MultiMedia Editora, 2015. p. 79-100.

MOTA, K. M. S. O tripé identidade, língua e nação nas falas de jovens brasileiros imigrantes nos Estados Unidos. Trab. Ling. Aplic., Campinas, v. 47, n. 2, p. 309- 322, jul./dez. 2008.

RIGGS, F. W. Diasporas and ethnic nations: causes and consequences of globalization. 2000. Disponível em: <http:// www2.hawaii.edu/ fredr/diaglo.htm\#definition>. Acesso em: 21 maio 2020.

SOUZA, Ana. How linguitic and cultural identites are affected by migration. Language Issue, London, v. 19, n. 1, p. 36-42, 2008. Disponível em: <https://souzaana.files.wordpress.com/2013/12/ souza-a-2008-linguistic-and-cultural-identities.pdf $>$ Acesso em: 14 mar. 2021.

TAJFEL, H. The social psychology of minorities. Londres: Minority Rights Group, 1978.

WEISS, D. B.; CANDIAN, M. Reflections on Brazilian Portuguese as a heritage language. Portuguese Language Journal(PLJ), New Jersey, v. 13, p. 13-29, Fall 2019. Disponível em: <https://5bd557bc-f877-4bcc-a0d0-27281d46ace8.filesusr. com/ugd/02e26d_6a43315171a640199e6827f71cdf279a.pdf $>$. Acesso em: 15 mar. 2021.

WEISS, D. B.; FONSECA, A. A.; DUTRA, M. C. P. Memória fonológica de falantes de Português brasileiro como língua de herança. Domínios de Lingu@gem, Uberlândia, v. 12, n. 2, p. 1.267-1.293, 2018. Disponível em: <http://www.seer.ufu.br/ index.php/dominiosdelinguagem/article/view/40099/22388>. Acesso em: 15 mar. 2021. 
ANEXO A - Questões do formulário preenchido pelos respondentes

Português como Língua de Herança

Neste formulário, você vai contar um pouco da sua história individual como brasileiro/a com filhos, morando fora do Brasil.

Seu primeiro nome é

Local de nascimento - cidade e estado

Idade com que saiu do Brasil

Onde mora atualmente? Cidade e estado

Qual a nacionalidade do seu marido/sua esposa?

Quantos filhos você tem?

Que idade ele/eles têm?

Línguas em casa

Que língua você usa mais frequentemente para falar com seu marido/com sua esposa?

Que língua você usa mais frequentemente para falar com seus filhos?

Que língua seu marido/sua esposa usa mais frequentemente para falar com você?

Que língua seu marido/sua esposa usa mais frequentemente para falar com os filhos?

Que língua seus filhos usam mais frequentemente para falar com você?

Que língua seus filhos usam mais frequentemente para falar com seu marido/sua esposa?

Que língua seus filhos usam mais frequentemente para falar 
entre si?

De que modo você participa dessa comunidade?

Grupo social (de amigos)

Grupo religioso

Grupo cultural (teatro, música, dança ou outras atividades)

Grupo esportivo (futebol, capoeira ou outra atividade)

Outro:

Existe uma comunidade brasileira na sua cidade?

Sim

Não

Talvez, mas eu não conheço.

De que maneira você participa dessa comunidade?

Grupo social (de amigos)

Grupo religioso

Grupo cultural (teatro, música, dança ou outra atividade)

Grupo esportivo (futebol, capoeira ou outra atividade)

Outro:

Marque as atividades que você costuma fazer sozinha ou com outros membros da sua família

Assistir a filme em português

Ouvir música em português

Assistir a novela brasileira

Assistir a TV brasileira

Por que você considera importante que seus filhos saibam falar português?

O que você faz para incentivar seus filhos a falarem português? 